\title{
A PERMANÊNCIA DA ESCRAVIDÃO NOS GARIMPOS DO ESTADO DO PARÁ A PARTIR DA UTILIZAÇÃO DE INSTRUMENTOS ESTATAIS: A NECESSIDADE DE FISCALIZAÇÃO E CONTROLE EFICIENTES
}

\author{
Otávio Bruno da Silva Ferreira1 \\ Valena Jacob2
}

\section{Resumo}

A escravização do ser humano viola a sua dignidade. Indaga-se como a utilização de instrumentos legais concorre para a existência do trabalho escravo contemporâneo nos garimpos do Estado do Pará. Objetiva-se identificar possíveis ações para coibir a utilização de tais instrumentos. Para tanto, discutir-se-á a caracterização do trabalho escravo contemporâneo, as condições de trabalho dos garimpeiros e a utilização daqueles. A partir do método dedutivo, de pesquisa qualitativa, aplicada, do tipo exploratória, com a realização de pesquisas bibliográficas e documental, conclui-se que a utilização de instrumentos legais tem relação direta com a manutenção do trabalho escravo.

Palavras-chave: Garimpo; Escravidão contemporânea; Sofisticação das fraudes; Trabalho degradante.

\section{THE PERMANENCE OF SLAVERY IN THE MINES OF THE STATE OF PARÁ FROM THE USE OF STATE INSTRUMENTS: THE NEED FOR EFFICIENT SUPERVISION AND CONTROL}

\begin{abstract}
The enslavement of human beings violates their dignity. It is questioned how the use of legal instruments contributes to the existence of contemporary slave labor in the mines of the State of Pará. The objective is to identify possible actions to curb the use of such instruments. Therefore, the characterization of contemporary slave labor, the working conditions of miners and their use will be discussed. From the deductive method, qualitative research, applied, exploratory type, with bibliographic and documentary research, it is concluded that the use of legal instruments is directly related to the maintenance of slave labor.
\end{abstract}

Keywords: Garimpo; Contemporary slavery; Sophistication of frauds; Degrading work.

1 Doutorando em Direitos Humanos pela Universidade Federal do Pará. Mestre em Direitos, Políticas Públicas e Desenvolvimento Regional pelo Centro Universitário do Estado do Pará. Professor da disciplina Direito do Trabalho no curso de pós-graduação do Centro Universitário FIBRA. Professor convidado nos cursos de pósgraduação do Centro Universitário do Estado do Pará e do Centro Universitário FIBRA. Juiz do Trabalho do Tribunal Regional do Trabalho da $8^{\text {a }}$ Região. E-mail: otavio.ferreira@trt8.jus.br

2 Doutora e Mestre em Direito pela UFPA. Professora da Graduação e do Programa de Pós-Graduação em Direito da UFPA; Diretora Geral do Instituto de Ciências Jurídicas da UFPA. Pesquisadora da Clínica de Direitos Humanos da Amazônia/UFPA. Líder do Grupo de Pesquisa CNPQ: Novas formas de trabalho, velhas práticas escravistas (dgp.cnpq.br/dgp/espelhogrupo/5232633034974997). Diretora da Escola Judicial da Associação Brasileira de Advogados Trabalhistas - ABRAT e Diretora da Associação Luso Brasileira de Juristas do Trabalho - JUTRA. e-mail: valenajacob@ufpa.br 


\section{Introdução}

A despeito da Constituição Federal Brasileira de 1988 ter como fundamento a dignidade da pessoa humana e haver a tipificação legal de determinadas condutas como crimes no Código Penal Brasileiro, permanecem atuais práticas de redução do ser humano à condição análoga à de escravo.

A exploração do ser humano é identificada em diversas cadeias produtivas e/ou empreendimentos, especialmente pelo fato de sua ocorrência estar relacionada à precariedade e a pobreza em que vivem milhares de brasileiros e a exploração desenfreada por mais-valia, com supressão de direitos trabalhistas mínimos.

Nesse cenário, a atividade de garimpo, no Estado do Pará, vem despontando como cenário fértil para a prática de escravidão contemporânea, aliado ao antecedente histórico que caracteriza os garimpeiros como um grupo social heterogêneo e historicamente vulnerável, que trabalham sem carteira assinada e sem o recebimento de outros direitos trabalhistas.

Segundo levantamento feito pelo Observatório da Mineração (2020), desde 2008, 333 trabalhadores foram resgatados em garimpos no Brasil em condições análogas à escravidão, em 31 operações, tendo o Pará ocupado destaque em 12 delas. Neste cenário, a cidade de Itaituba, no médio Tapajós no Pará, se destaca como o maior polo de mineração ilegal do Brasil, com estimativa de que mais de 60 mil garimpeiros trabalhem na região, com 1.000 pistas de pouso para aviões.

Nas operações de resgate, os trabalhadores foram encontrados em condições precárias, em locais sem instalações adequadas para alojamento, sem banheiros, consumindo água contaminada, com alimentação improvisada, sem equipamento de proteção, cumprindo jornadas exaustivas, sem vínculo formal e, não raro, submetidos a dívidas acumuladas com o dono do garimpo, o que caracteriza o trabalho em condição análoga à de escravo.

Além disso, os garimpos sofisticaram a sua forma de atuação, por meio da utilização de instrumentos lícitos, como o Cadastro Ambiental Rural (CAR), a constituição de cooperativas de garimpeiros e a autorização para a realização da atividade mineradora, com o intuito de aumentar a área de mineração e mascarar os vínculos empregatícios, com claro propósito de manutenção da escravização dos garimpeiros.

A partir do cenário exposto, o presente estudo busca responder o seguinte problema: como a utilização de instrumentos legais vem concorrendo para a existência do trabalho 
escravo contemporâneo nos garimpos do Estado do Pará?

Para tanto, traça-se como objetivo geral a identificação de possíveis instrumentos e condutas para coibir o trabalho escravo contemporâneo nos garimpos no Pará. Traçam-se, como objetivos específicos: a) discutir a caracterização do trabalho escravo contemporâneo; b) analisar as condições de vida e de trabalho identificadas nas fiscalizações realizadas nos garimpos e c) identificar os instrumentos lícitos utilizados pelos proprietários dos garimpos.

Quanto aos aspectos metodológicos, o estudo está estruturado em método dedutivo, pesquisa qualitativa, aplicada, do tipo exploratória, com a realização de pesquisas bibliográficas e o exame de relatórios de fiscalização e processos judiciais. Neste ponto, delimita-se que serão analisados Relatórios de Fiscalização de ações realizadas nos garimpos Coatá, no ano de 2018, e Pau Rosa, no ano de 2020, ambos localizados na região do Tapajós, no Pará.

Além da introdução e considerações finais, o estudo encontra-se dividido em três seções, cada uma correspondendo a um dos objetivos específicos propostos.

$\mathrm{Na}$ primeira seção, analisa-se o conceito de trabalho em condição análoga à de escravo, com a apresentação de recortes teóricos, bem como o texto do artigo 149 do Código Penal Brasileiro, com destaque e delimitação para o estudo do trabalho em condição degradante.

Na segunda seção, faz-se um estudo sobre as condições de vida e de trabalho do trabalhador escravizado no garimpo, com fundamento nos relatórios de fiscalização. Na terceira seção, abre-se espaço para tratar sobre os instrumentos utilizados pelos escravizadores para a sofisticação das fraudes e dos crimes. Por fim, segue-se para as considerações finais, com a resposta ao problema de pesquisa formulado.

Entende-se que o estudo é socialmente relevante, considerando a quantidade de pessoas exploradas em um das atividades mais rentáveis no Pará, e juridicamente pertinente.

\section{Considerações sobre o Trabalho Escravo Contemporâneo e o Trabalho Degradante}

É difícil a tarefa de produzir um conceito uníssono sobre o tema em estudo em decorrência da pluralidade de entendimentos quanto à definição, à caracterização e à delimitação do trabalho análogo ao de escravo, bem como dada a existência de diversas condutas que permitem denotar aquela condição, não se limitando à mera privação de 
liberdade de locomoção.

Por certo, a inexistência de entendimento sobre o alcance da prática apresenta entrave para a sua erradicação, considerando a necessidade de ações coordenadas que envolvam áreas distintas da ciência jurídica, as quais, não raro, apresentam divergências quanto ao enquadramento dos fatos relacionados ao trabalho análogo ao de escravo. A discussão sobre a dificuldade de caracterizar o trabalho em condição análoga à de escravo não se limita ao âmbito acadêmico, ao contrário, transita para a seara decisória do Poder Judiciário e para a área fiscalizatória do Poder Executivo.

Segundo Silva (2010), a escravidão é o exercício, relativamente a uma pessoa, de um poder ou de um conjunto de poderes que traduzam um direito de propriedade ou o estado ou condição de um indivíduo sobre o qual se exercem, total ou parcialmente, os atributos do direito de propriedade, por consequência, toda a esfera da dignidade da pessoa humana, que se vê aviltada não apenas em sua liberdade e igualdade, mas em sua própria condição de ser humano.

Nesse sentido, entende-se que a escravidão é exatamente a coisificação do homem, que atinge toda a sua dignidade enquanto pessoa humana, não se limitando aos direitos relativos à sua liberdade e igualdade.

Oportuno registrar que, de acordo com Brito Filho (2018), o crime de redução da pessoa à condição análoga à de escravo consiste na subjugação do ser humano, naturalmente livre, a uma condição que lhe impõe uma relação de domínio extremado por outrem, que atenta contra a sua condição de pessoa. Não é toda e qualquer espécie de subordinação, mas a exploração extrema de seres humanos juridicamente livres, mas faticamente subjugados. Assim, analisa-se o grau de domínio e de sujeição que o tomador do serviço impõe ao trabalhador.

A despeito da dificuldade, entende-se necessário discutir a extensão e o alcance das hipóteses de atividades que podem ser enquadradas no tipo penal previsto no art. 149 do Código Penal Brasileiro $^{3}$ (BRASIL, 1940), com a redação dada pela Lei $n^{\circ} 10.803$, de 11 de

3 Art. 149. Reduzir alguém a condição análoga à de escravo, quer submetendo-o a trabalhos forçados ou a jornada exaustiva, quer sujeitando-o a condições degradantes de trabalho, quer restringindo, por qualquer meio, sua locomoção em razão de dívida contraída com o empregador ou preposto:

Pena - reclusão, de dois a oito anos, e multa, além da pena correspondente à violência.

$\S 1^{\circ}$ Nas mesmas penas incorre quem:

I - cerceia o uso de qualquer meio de transporte por parte do trabalhador, com o fim de retê-lo no local de trabalho; 
dezembro de 2003.

Antes da alteração legislativa, o tipo penal tinha a seguinte redação: "Art. 149 Reduzir alguém a condição análoga à de escravo" (sic). A despeito de ser uma norma aberta e, aparentemente, permitir a inclusão de diversas condutas, pela sua própria natureza de norma penal proibitiva, acabava revelando-se insatisfatória para a tipificação e a delimitação dos fatos analisados. Assim, a alteração legislativa, ao dispor especificamente sobre as hipóteses de ocorrência do crime, permitiu a melhoria de sua compreensão e facilitou o enquadramento pelas autoridades competentes.

A respeito do dispositivo, é oportuno tecer algumas considerações. A primeira é que, a despeito de estar situado no capítulo VI - Dos crimes contra a liberdade individual, na seção I, que trata dos crimes contra a liberdade pessoal, o bem jurídico tutelado não é apenas a liberdade de locomoção, ao contrário do entendimento anteriormente dominante, embora a violação à liberdade ampla esteja sempre presente na hipótese de cometimento de alguma das espécies previstas no tipo penal. Trata-se, de fato, de violação a vários direitos, dentre eles, à saúde, à vida e à segurança do trabalhador, todos direcionados à garantia de sua dignidade.

A segunda consideração é a mudança significativa de alteração dos bens jurídicos tuteláveis, que passou da liberdade para a dignidade do ser humano (BRITO FILHO, 2018), assinalando que não importa considerar apenas a dignidade como tutelável, mas a reputar o bem maior a ser protegido.

Considerando a redação atual do tipo penal, entende-se que a condição análoga à de escravo caracterizar-se-á na ocorrência das seguintes hipóteses: a) trabalho forçado; b) trabalho com jornada exaustiva; c) trabalho em condição degradante; d) trabalho com restrição de locomoção em razão de dívida; e) retenção do trabalhador no local de trabalho em virtude de cerceamento do uso de qualquer meio de transporte; f) retenção do trabalhador no local de trabalho em virtude do apoderamento de seus documentos ou objetos pessoais e; g) vigilância ostensiva.

A existência de um rol analítico de condutas auxilia na identificação e no enquadramento das práticas que são investigadas, orientando o trabalho dos responsáveis pelas investigações, autuações e ações cabíveis.

II - mantém vigilância ostensiva no local de trabalho ou se apodera de documentos ou objetos pessoais do trabalhador, com o fim de retê-lo no local de trabalho.

$\$ 2^{\circ}$ A pena é aumentada de metade, se o crime é cometido:

I - contra criança ou adolescente;

II - por motivo de preconceito de raça, cor, etnia, religião ou origem. 
Ao contrário dos demais casos de ocorrência do tipo penal que são quase autoexplicativos, o trabalho degradante envolve, para a sua caracterização, uma série de variáveis e fatores, o que exige, para a sua compreensão e aplicação, um esforço maior em decorrência dos debates que envolvem a temática.

No plano normativo, embora as Convenções no 29 (OIT, 1930) e 105 (OIT, 1957), ambas da OIT, sobre o trabalho forçado, não tenham disposto especificamente sobre o trabalho em condições degradantes, o Brasil aprovou várias normas que o proíbem expressamente. Neste contexto, aponta-se o Pacto Internacional dos Direitos Civis e Políticos, de 1966 (ONU, 1966), o qual prevê, em seu art. $7^{\circ}$, que ninguém poderá ser submetido à tortura, nem a penas ou tratamentos cruéis, desumanos ou degradantes. No mesmo sentido, a Convenção Americana de Direitos Humanos, de 1969 (OEA, 1969), dispõe, em seu art. 5º itens 1 e 2, que toda pessoa tem direito a que se respeite sua integridade física, psíquica e moral e que ninguém deve ser submetido a torturas, nem a penas ou tratos cruéis, desumanos ou degradantes.

Além disso, no plano interno, a Constituição Federal, no art. $1^{\circ}$, inc. III (BRASIL, 1988), elenca, dentre os princípios fundamentais da República Federativa do Brasil, a dignidade da pessoa humana, ao mesmo tempo em que, no art. $5^{\circ}$, inc. III, consta a previsão de que ninguém será submetido à tortura nem a tratamento desumano ou degradante.

Para Melo (2004), o trabalho degradante é caracterizado por péssimas condições de trabalho e de remuneração, como a utilização de trabalhadores intermediados por gatos ou cooperativas de mão de obra fraudulentas; a utilização de trabalhadores arregimentados por gatos em outras regiões; a submissão de trabalhadores a precárias condições de trabalho, pela ausência de boa alimentação e água potável ou pelo seu fornecimento inadequado; o fornecimento de alojamentos sem as mínimas condições de habitação e sem instalações sanitárias; a cobrança pelos instrumentos necessários à prestação dos serviços e pelos equipamentos de proteção individuais, como chapéus, botas, luvas, caneleiras, etc.; o não fornecimento de materiais de primeiros socorros; o fornecimento de transporte inseguro e inadequado aos trabalhadores; e o descumprimento generalizado da legislação de proteção ao trabalho, como a ausência de registro do contrato na CTPS, a não realização de exames médicos admissionais e demissionais e o não pagamento de salário ao empregado.

Brito Filho (2018) considera que o trabalho em condições degradantes é aquele no qual inexistem condições mínimas de saúde e de segurança, além da falta de condições 
mínimas de trabalho, de moradia, higiene, respeito e alimentação, fornecidas em conjunto, vez que a ausência de fornecimento de um deles impõe o reconhecimento da situação de trabalho degradante.

No mesmo sentido, Andrade (2006) entende que o trabalho degradante é aquele que priva o trabalhador de sua dignidade, que o despreza como sujeito de direitos, que o rebaixa e deteriora sua saúde, desenvolvido sob péssimas condições e com remuneração incompatível, sem garantias mínimas à sua segurança e saúde e com limitação à alimentação e moradia.

Com base nos entendimentos acima, identifica-se que o trabalho em condições degradantes é caracterizado pela ausência de direitos mínimos relacionados à saúde e à segurança do trabalhador, com exposição de sua integridade física e psíquica, bem como pela inexistência de um rol mínimo de direitos, como alojamento, água e alimentação adequada, não pagamento de salários, submissão a tratamentos desumanos, todos praticados com clara violação de sua dignidade.

Feita a abordagem sobre a caracterização do trabalho em condição análoga à de escravo, na hipótese de trabalho degradante, passa-se ao exame das condições de vida e de trabalho dos garimpeiros que atuam no Estado do Pará, nos garimpos Coatá e Pau Rosa.

\section{As condições de vida e de trabalho nos garimpos: garimpos Coatá e Pau Rosa}

A fim de identificar as condições de vida e de trabalho suportadas pelos trabalhadores que atuam na extração do minério no Estado do Pará, entende-se importante apresentar os registros feitos pelas fiscalizações realizadas pelo Grupo Móvel de Fiscalização ao Trabalho Escravo.

A operação do Grupo Especial de Fiscalização Móvel (GEFM) realizada em agosto de 2018, resgatou 38 trabalhadores no garimpo Coatá, em Jacareacanga - Pará. No Relatório Preliminar de Fiscalização (BRASIL, 2018) consta que a produção dos garimpeiros e o valor devido às cozinheiras eram anotados pela proprietária do empreendimento em um caderno que ficava em sua posse, na cantina da sede do garimpo, onde ficavam disponíveis bebidas alcoólicas, mantimentos e medicamentos para a venda aos trabalhadores, sendo tudo cobrado em ouro e anotado em outro caderno, com preços acima dos valores de mercado.

No término contratual, o acerto das contas era feito pela somatória da produção do garimpeiro com a subtração dos valores relativos à sua conta na cantina. Se o trabalhador 
ficasse com débito, normalmente permaneceria mais tempo trabalhando até pagar o que devia. Se a diferença fosse positiva, o garimpeiro recebia em ouro e podia sair do garimpo.

No caderno de dívidas, também eram anotados os valores devidos pelos garimpeiros às cozinheiras, que lhes prestavam serviços sexuais. Tudo passava pela coordenação e orientação da proprietária do garimpo, que recebia a informação do garimpeiro e transferia o valor para o registro de crédito da cozinheira, além da própria instituição da regularidade de prestação de serviços sexuais pelas cozinheiras, que eram contratadas dentre mulheres solteiras, com expressa vedação de manter relacionamento estável com algum garimpeiro, sob pena de expulsão do local.

Quanto ao aliciamento dos trabalhadores e trabalhadoras, este ocorria na cidade de Itaituba - Pará, sendo que as despesas com o adiantamento do dinheiro para a família, transporte e alimentação, já se transformavam em dívida. No local, devido ao isolamento do garimpo e a falta de sinal para celular, os garimpeiros ficavam sem contato com suas famílias.

Os trabalhadores, em cada uma das frentes de trabalho, encontravam-se alojados em barracos de lona plástica próximos às áreas em que se desenvolviam as atividades de garimpagem (regionalmente denominadas "pistas"). A estrutura dos barracos estava localizada em clareiras abertas no interior da floresta, cujo acesso dava-se por estradas internas ou por trilhas no interior da mata, em locais isolados e de difícil acesso. As áreas, após o desmatamento, eram preparadas por retroescavadeiras pertencentes à proprietária. Também eram escavadas pequenas cacimbas, com cerca de 3 a 4 metros de profundidade e sobre essa cacimba os trabalhadores faziam um pequeno telhado de madeira coberto com lona plástica, sem qualquer proteção das paredes, onde se filtrava a água usada para o consumo, alimentação e banho dos trabalhadores.

Consta ainda que cada uma das frentes de trabalho eram constituídas por um grupo de 3 a 5 garimpeiros e uma cozinheira. Os barracos foram construídos pelos próprios trabalhadores, com uso de toras rústicas de madeira retiradas da mata e amarradas com cipó titica, cobertas com lona plástica preta e encerados azuis fornecidos pela proprietária do garimpo.

Os garimpeiros ficavam alojados coletivamente em uma área construída e coberta, mas sem qualquer parede e com chão de terra nua (não batida). O local era utilizado para esticar as redes utilizadas para dormir (pertencente aos próprios trabalhadores), assim como para pendurar sacolas, mochilas, e sacos de aniagem utilizados para a guarda dos poucos 
pertences individuais de cada um; era frequente o uso de pequenos jirais ou mesas improvisadas com toras roliças de madeira para guardar tais pertences e pendurar roupas e toalhas.

Em uma estrutura à parte, construída do mesmo modo já descrito, havia outro barraco utilizado como cozinha, com fogão à lenha (ou à gás, encontrado em alguns locais) e pequenas mesas e prateleiras improvisados para a guarda de sacos de mantimentos (arroz, feijão, sal, óleo, farinha, macarrão).

Por outro lado, a água utilizada para o preparo dos alimentos e a lavagem da louça era retirada das cacimbas e armazenadas em tambores de 200 litros, sem tampas, mantidas nas cozinhas e apresentavam aspecto extremamente turvo, com muitas partículas em suspensão e era utilizada sem qualquer tratamento ou cuidado com sua pureza. Para minimizar a má qualidade, os trabalhadores cobriam a cacimba com pequenos retalhos de lona plástica, os quais não impediam a entrada e escorrimento de água da chuva e toda a sorte de sujidades, animais e insetos.

Anexo às cozinhas havia um local reservado, cercado de lona plástica, utilizado como dormitório pelas cozinheiras, além de um pequeno cercado plástico, com chão de tábuas soltas, para a cozinheira se banhar com a água proveniente das citadas cacimbas, sem chuveiros. No barraco das cozinheiras também encontramos colchões mantidos sobre estrados improvisados com madeiras roliças, sem a presença de armários individuais.

Não havia instalações sanitárias nos barracos e nas frentes de serviço, de modo que todas as necessidades eram feitas no mato. Em apenas um dos barracos, os trabalhadores improvisaram um pequeno cercado de lona para fazer as necessidades fisiológicas em um buraco de $2 \times 3$ metros, com cerca de 3 metros de profundidade, com risco de queda e odor fétido, sem qualquer cobertura, onde se agachavam em troncos lisos para defecar.

Para o banho, a maioria dos garimpeiros utilizava pequenas grotas ou igarapés, ao ar livre, sem qualquer conforto e privacidade. Em alguns locais encontramos cercados de lona plástica, sem coberturas, onde alguns trabalhadores se banhavam com a água das cacimbas, por meio de pequenos potes plásticos ou canecas.

Os trabalhadores faziam a refeição no próprio barranco, procurando uma sombra para se abrigar.

Das narrativas acima, constata-se a ilegal forma de exploração do trabalho humano, notadamente quanto ao não fornecimento de alojamentos, não fornecimento de equipamentos 
de proteção individual, não fornecimento de água potável (situação de exposição a insegurança hídrica) e não fornecimento de instalações sanitárias, submetendo os trabalahdores e as trabalhadoras a condições degradantes e a submissão a jornada exaustiva, reduzindo-os à condição análoga a de escravos.

Em nova incursão realizada no período de 24/09/2018 a 28/09/2018, constatou-se a continuidade das condutas irregulares, conforme se observa no Adendo ao Relatório de Fiscalização (BRASIL, 2018b).

Com base nas constatações acima, o Ministério Público do Trabalho ingressou com Ação Civil Pública, autuada sob o $\mathrm{n}^{\circ}$ 0000606-06.2018.5.08.0113, em trâmite na Vara do Trabalho de Itaituba, atualmente na fase de cumprimento de acordo. Neste processo, foi celebrado acordo, em 12/12/2019, que, além da obrigação de pagar, envolveu o cumprimento de uma série de obrigações de fazer e de não fazer pelo empregador, especialmente voltadas ao tratamento digno dos trabalhadores e à cessação da prática de escravidão contemporânea.

Não obstante o acordo citado, em dia 26/10/2020, o Grupo Especial de Fiscalização Móvel - GEFM, esteve presente em outras três frentes de trabalho de garimpo, situadas no Garimpo do Pau Rosa, localizado no município de Jacareacanga, a 310 quilômetros de Itaituba, no Pará, e a fiscalização constatou que os 39 trabalhadores estavam submetidos à condição análoga à de escravos, mantidos em condições degradantes de trabalho e de vida.

Identificou-se no Relatório Preliminar de Fiscalização (BRASIL, 2020) que nenhum dos trabalhadores tinha sua CTPS anotada, não dispunham, na primeira frente, de alojamento, eis que dormiam em barracos cobertos de lona, sem qualquer proteção contra intempéries e possíveis ataques de animais silvestres. Na segunda e terceira frentes, havia alojamentos construídos de madeira, porém também sem condições adequadas de instalação. Não havia portas, nem janelas, nem banheiros. Para dormir, havia apenas redes, sem roupa de cama ou coberta. A água era captada diretamente pelos trabalhadores, aparentando não ser apta à ingestão humana. A alimentação era preparada numa mesa improvisada, sendo que o cômodo não dispunha nem de fornecimento de água nem de esgoto. Os gêneros de primeira necessidade, os equipamentos de proteção individuais (inadequados) e demais outras necessidades eram fornecidos pelos empregadores a preço de ouro. Este garimpo era explorado por familiares da proprietária do garimpo fiscalizado em 2018.

Identifica-se, da cotejo entre as apurações realizadas nos anos de 2018 e 2020, que há, nos municípios de Itaituba e Jacareacanga, no Pará, um empreendimento familiar que vem 
submetendo dezenas de trabalhadores a condições análogas à escravidão. A reincidência em tal prática, instiga a necessária compreensão sobre como uma atividade criminosa vem se perpetuando, a despeito da proibição legal, ou seja, como a atividade vem se sofisticando.

\section{A utilização dos instrumentos para a sofistificação das fraudes nos garimpos}

A reincidência da prática de escravização de trabalhadores não ocorre por acaso. É possível identificar, especificamente no cenário relatado acima, a utilização de diversos instrumentos previstos na legislação com o intuito de afastar a caracterização de ilicitude da atividade.

Segundo Mongabay (2020), mesmo após a operação de 2018, a proprietária do Garimpo Coatá e seus filhos, registraram requerimentos minerários na Agência Nacional de Mineração (ANM), órgão federal ligado ao Ministério de Minas e Energia, e obtiveram a aprovação de quatro deles. Assinala ainda que, em outubro de 2018, dois meses após a primeira operação do GEFM acima referida, a proprietária do garimpo conseguiu uma permissão de lavra garimpeira em Itaituba, com validade até o ano de 2023. Outro requerimento de pesquisa, datado de 2011, segue em trâmite. Já seu filho, responsável pela administração dos garimpos, protocolou oito requerimentos de pesquisa e lavra na ANM entre 2018 e 2020. E ainda obteve três autorizações concedidas para pesquisa, todas válidas até 2022.

Segundo o Ministério Público Federal (2020), a simplicidade e a desnecessidade de prévia pesquisa mineral orientam, como regra, os requerimentos de Permissão de Lavra Garimpeira - PLG, e que essas características contribuíram para que proliferassem milhares de requerimentos de PLGs na Amazônia, numa prática sistemática e escancarada que visa à reserva de mercado e que configura manifesto abuso de direito, em específico do direito de prioridade.

Assinala ainda que a proliferação indiscriminada de requerimentos de PLGs na Amazônia, à míngua de uma atividade efetivamente regulatória por parte da ANM, tem relegado ao exclusivo alvedrio da iniciativa privada a afetação de novas áreas para a exploração mineral, tem estimulado a pressão pela recategorização de unidades de conservação e a conversão predatória de terras indígenas e de áreas de floresta para atividades minerárias (MINISTÉRIO PÚBLICO FEDERAL, 2020). 
É importante destacar que garimpeiro é toda pessoa física de nacionalidade brasileira que, individualmente ou em forma associativa, atue diretamente no processo da extração de substâncias minerais garimpáveis, a teor do artigo 2º I, da Lei 11.685/08 (Estatuto do Garimpeiro) e que a concentração de várias PLGs nas mãos de um mesmo requerente termina por desqualificá-lo como garimpeiro, pois não é possível a uma pessoa física atuar diretamente em mais de uma PLG, tendo a própria lei estabelecido o limite de 50 hectares para cada área permitida. Os garimpeiros, que dependem de seu trabalho para sobreviver, perdem o espaço para aqueles que legalmente não podem ser definidos como garimpeiros.

O registro de requerimentos na ANM é parte da sofisticação do crime, pois tem o objetivo de dar uma aparência de legalidade aos garimpos instalados na região.

Outro instrumento utilizado foi a criação, em 2020, de uma cooperativa de garimpeiros no Pará, tendo a proprietária do garimpo como presidente e seus filhos como diretores. A instituição de cooperativa tem o condão de mascarar as condições reais dos trabalhadores e dos próprios garimpos, negar a existência de vínculo de emprego e aparentar que os trabalhadores estão organizados em prol do coletivo por conta própria, sem exploração por outrem.

É certo que a lei apoia e estimula o cooperativismo e outras formas de associativismo, e que o Estado favorece a organização da atividade garimpeira em cooperativas, levando em conta a proteção do meio ambiente e a promoção econômico-social dos garimpeiros e que tais cooperativas terão prioridade na autorização ou concessão para pesquisa e lavra dos recursos e jazidas de minerais garimpáveis. Todavia, a concentração de mais de uma PLG em mãos de uma mesma pessoa física frustra o favorecimento da atividade de garimpagem em cooperativas, prejudicando, além da proteção do meio ambiente, a promoção econômica e social dos garimpeiros.

Além das cooperativas, outra forma utilizada para mascarar os vínculos empregatícios é a celebração de contratos de parceria, a despeito de presentes todos os requisitos da relação de emprego, a saber: pessoalidade, não eventualidade, subordinação e onerosidade (BRASIL, 2018).

Além disso, outro instrumento apontado na investigação conduzida pela Mongabay (2020) é a solicitação de registro no Cadastro Ambiental Rural (CAR), que vem sendo utilizado, na prática, como instrumento da grilagem de terras, servindo aos propósitos do garimpo ilegal. Foram identificados onze pedidos de registros, todos feitos em abril e maio 
de 2018, nos nomes de pessoas da família da proprietária do Garimpo Coatá, que totalizam mais de 7 mil hectares registrados nos nomes deles, nos municípios de Itaituba, Jacareacanga e Rurópolis.

O registro da suposta propriedade da terra, autodeclaratória e não equivalente a um título legal, é mais um passo na direção de forjar um cenário de "busca pela regularização".

Ponto em comum entre os instrumentos mencionados é que a cooperativa, quase todos os requerimentos na ANM e os registros no CAR foram feitos a partir de 2018, época da primeira operação, o que evidencia um esforço coordenado na tentativa de transparecer certa licitude nas atividades.

Além da utilização desses instrumentos, outro ponto relativo à sofisticação é a técnica utilizada para tirar o ouro dos funcionários. A proprietária do empreendimento é o banco e o comércio do local, responsável pela guarda do pagamento dos funcionários, utilizando-o para os descontos dos gastos deles no garimpo. Ou seja, o garimpeiro nunca recebe o salário em espécie, pois as transações realizadas entre comércio e banco, em uma só pessoa, retiram-lhe o poder de usufruir dos recursos que obterei com seu trabalho.

Apresentados os instrumentos de sofisticação da atividade, passa-se ao exame de como coibir ou reduzir a sua ocorrência.

\section{Considerações Finais}

A pesquisa e a exploração mineral, representando uma das atividades mais rentáveis do Estado do Pará, vem se apresentando também como uma das atividades promissoras para a escravização do ser humano. No estudo feito, identificou-se que a região do Tapajós concentra um dos maiores garimpos ilegais do mundo. Ao lado da ilicitude da própria exploração mineral, há diversos outros crimes, dentre os quais, a redução do trabalhador à condição análoga a de escravo.

Por certo, a identificação da exploração no ano de 2018, a fiscalização, a suspensão da atividade, a celebração de acordo em ação judicial, não fizeram cessar o crime, tanto que foi novamente identificado no ano de 2020, com reprodução das mesmas condições de vida e de trabalho identificadas dois anos antes.

A permanência da escravização ocorre, além de outros motivos, pela sofisticação do modo de atuação, representada pela utilização de instrumentos legais, que são utilizados de 
forma ilegal para mascarar a atividade. Nesse cenário, foram identificadas os seguintes instrumentos: i) requerimentos de Permissão de Lavra Garimpeira; ii) concentração de requerimentos de PLGs; iii) constituição de cooperativa de garimpeiros no Pará ilícitas; iv) celebração de contratos de parceria; v) solicitação de registro no Cadastro Ambiental Rural (CAR) e vi) remodelação de técnica utilizada para tirar o ouro dos funcionários.

Nota-se que os instrumentos citados, e agora respondendo ao problema que norteou esse estudo, estão diretamente relacionados à existência e permanência do trabalho escravo contemporâneo. Isto porque há clara remodelação da atuação a fim de mascarar a escravização, pois, com sabido, para a caracterização daquele crime é indispensável a existência de um contrato de trabalho entre as partes. Inexistindo tal contrato, seja por meio das cooperativas ou por meio dos contratos de parceria (itens III e IV), seria inócua a ação fiscalizatória em decorrência da ausência do vínculo citado.

Além disso, os instrumentos mencionados nos itens I e II inviabilizam a formação de cooperativas lícitas, pois privam o trabalhador de acesso às propriedades, em decorrência da concentração fundiária. Tal cenário aumenta a precarização e a pobreza da população, tornando-a vulnerável à escravização.

Por fim, o item IV apresenta a hipótese de escravidão por dívida. Ou seja, os instrumentos identificados estão diretamente relacionados à ocorrência do trabalho escravo contemporâneo, exigindo ações efetivas para eliminar as fraudes existentes nos requerimentos, solicitações de registros e relações contratuais.

Com o mesmo objetivo destacado, o Ministério Público Federal apresentou uma série de recomendações à Agência Nacional de Mineração, dentre as quais, destacam-se: o indeferimento de todos os requerimentos de PLGs feitos por pessoa que já seja titular de PLG, feitos por pessoa que, embora não seja titular de PLG, tenha vários requerimentos em trâmite, mantendo-se apenas o mais antigo; instauração de procedimentos administrativos para promover o cancelamento de PLGs nos casos em que os beneficiários sejam titulares de mais de um título; que os pedidos novos e pendentes sejam analisados no prazo de 30 dias; que a ANM faça constar expressamente, nos protocolos de requerimento de PLG que, enquanto não deferidos, não se tratam de títulos minerários, mas de requerimentos precários, não negociáveis e que não autorizam a exploração mineral; que sejam rejeitados automaticamente todos os requerimentos de PLGs incidentes em terras indígenas e unidades de conservação; que a agência estabeleça critérios para favorecer a organização da atividade garimpeira em 
cooperativas, levando em conta a proteção do meio ambiente e a promoção econômico-social dos garimpeiros e que elabore estudo técnico que revise os limites da Reserva Garimpeira do Tapajós (MINISTÉRIO PÚBLICO FEDERAL, 2020).

Tratam-se, em resumo, de medidas de combate à concentração ilegal de requerimentos de Permissões de Lavra Garimpeira (PLGs) e de revisão dos limites da Reserva Garimpeira do Tapajós. Acrescenta-se a necessária e urgente realização de vistorias constantes na região para monitorar as ocorrências de trabalho escravo.

Por fim, destaca-se que a preservação da dignidade da pessoa deve nortear a conduta de todos, tanto do Estado quanto dos administrados. Assim, não há como prevalecer a livre iniciativa em face da violação dos direitos básicos dos trabalhadores. O núcleo essencial de proteção de todo ser humano deve ser respeitado, a fim de que sejam garantidas condições existenciais mínimas de vivência, de sobrevivência e de reprodução social.

\section{Referências}

ANDRADE, Denise Lapolla de Paula Aguiar. A servidão por dívidas e o princípio da dignidade humana. Apontamentos sobre trabalho escravo, forçado e degradante. Revista Synthesis: Direito do Trabalho Material e Processual, São Paulo, n. 42, p.11-16, 2006.

BRASIL. [Constituição (1988)]. Constituição da República Federativa do Brasil. Brasília, DF: Presidência da República. 1988. Disponível em: http://www.planalto.gov.br/ccivil_03/constituicao/constituicaocompilado.htm. Acesso em: 08 set. 2020.

BRASIL. Decreto-Lei no 2.848, de 7 de dezembro de 1940. Código Penal. Disponível em: https://www.planalto.gov.br/ccivil_03/decreto-lei/Del2848compilado.htm Acesso em: 08 set. 2020.

BRASIL. Ministério do Trabalho: Secretaria de Inspeção do Trabalho. Departamento de Fiscalização no Trabalho. Divisão de Fiscalização para Erradicação do Trabalho Escravo.

Relatório Preliminar de Fiscalização: Garimpo do Coatá. 2018. Período: 16.08.2018. Local: Jacareacanga. Documento extraído dos autos do processo no . 0000606-06.2018.5.08.0113, em trâmite na Vara do Trabalho de Itaituba.

BRASIL. Ministério do Trabalho: Secretaria de Inspeção do Trabalho. Departamento de Fiscalização no Trabalho. Divisão de Fiscalização para Erradicação do Trabalho Escravo. Adendo Preliminar ao Relatório de Fiscalização: Garimpo do Coatá. 2018. Operação: 071/2018. Local: Jacareacanga. Documento extraído dos autos do processo $\mathrm{n}^{\circ}$. 000060606.2018.5.08.0113, em trâmite na Vara do Trabalho de Itaituba. 
BRASIL. Ministério do Trabalho: Secretaria de Inspeção do Trabalho. Departamento de Fiscalização no Trabalho. Divisão de Fiscalização para Erradicação do Trabalho Escravo.

Relatório Preliminar de Fiscalização: Garimpo do Pau Rosa. 2020. Período: 26 a 28.10.2020. Local: Jacareacanga. Documento extraído dos autos do processo $\mathrm{n}^{\circ}$. 000060606.2018.5.08.0113, em trâmite na Vara do Trabalho de Itaituba.

BRASIL. Ministério Público Federal. Recomendação no 1, de 18 de março de 2020. Procuradoria da República do Município de Itaituba.

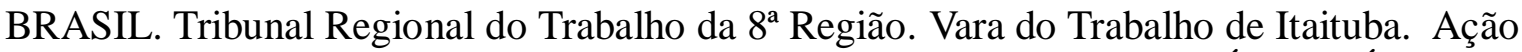
Civil Pública. Processo $\mathbf{n}^{\mathbf{0}}$ 0000606-06.2018.5.08.0113. Autor: MINISTÉRIO PÚBLICO DO TRABALHO. Reclamados: RAIMUNDA OLIVEIRA NUNES, TAMIS DANIELE OLIVEIRA TAVARES, RAIFRAN OLIVEIRA NUNES, TANIS DAISE OLIVEIRA CARDOSO e TAMIS DENES OLIVEIRA NUNES. Ajuizado em 06 set. 2018.

BRITO FILHO, José Claudio Monteiro de. Trabalho decente: análise jurídica da exploração do trabalho: trabalho escravo e outras formas de trabalho indigno. 5. ed. São Paulo: Ltr, 2018.

MELO, Luis Antônio Camargo de. As atribuições do Ministério Público do Trabalho na prevenção e no enfrentamento ao trabalho escravo. Revista LTr: Legislação do trabalho, São Paulo, v. 68, n. 4, abr. 2004. pp. 425-432.

MONGABAY. Trabalho escravo em garimpos expõe redes criminosas na Amazônia. Publicado em 11 de fev. 2021. Disponível em: https://brasil.mongabay.com/2021/02/trabalhoescravo-em-garimpos-expoe-redes-criminosas-na-amazonia/ Acesso em 08 set. 2021.

OBSERVATÓRIO DA MINERAÇÃO. Mais de 300 trabalhadores em condições análogas à escravidão foram resgatados em garimpos no Brasil. Publicado em 6 jul. 2021.

Disponível em: https://observatoriodamineracao.com.br/exclusivo-mais-de-300trabalhadores-em-condicoes-analogas-a-escravidao-foram-resgatados-em-garimpos-no-brasil/ Acesso em 08 set. 2021.

ORGANIZAÇÃO DAS NAÇÕES UNIDAS (ONU). Pacto Internacional sobre os Direitos Civis e Políticos de 1966. Disponível em:

http://www.dhnet.org.br/direitos/sip/onu/doc/pacto2.htm. Acesso em: 09 set. 2020.

ORGANIZAÇÃO DOS ESTADOS AMERICANOS (OEA). Convenção Americana de Direitos Humanos, de 1969. Disponível em:

https://www.cidh.oas.org/Basicos/Portugues/c.Convencao_Americana.htm. Acesso em: 09 set. 2020 .

ORGANIZAÇÃO INTERNACIONAL DO TRABALHO (OIT). Convenção no. 29. Trabalho Forçado ou Obrigatório. Genebra, 1930. Disponível em: https://www.ilo.org/brasilia/convencoes/WCMS_235021/lang--pt/index.htm. Acesso em: 09 set. 2020.

ORGANIZAÇÃO INTERNACIONAL DO TRABALHO (OIT). Convenção nº 105. Abolição do Trabalho Forçado. Genebra, 1957. Disponível em: 
https://www.ilo.org/brasilia/convencoes/WCMS_235195/lang--pt/index.htm. Acesso em: 09 set. 2020.

SILVA, Marcello Ribeiro. Trabalho análogo ao de escravo rural no Brasil do século XXI: novos contornos de um antigo problema. 2010. 280 f. Dissertação (Mestrado em Direito) Universidade Federal de Goiás, Goiânia, 2010. 